\title{
STRESS ANALYSIS OF REMOVABLE PARTIAL DENTURES OF DISTAL EXTENSION CASES FABRICATED OF TWO RECENT AESTHETIC CAD/CAM PROSTHETIC MATERIALS VERSUS CONVENTIONALLY MANUFACTURED METALLIC RPDS
}

\author{
Elsayed Gad Eid*
}

\begin{abstract}
Recently, there are different types of esthetic materials used for RPDs framework fabrication some of which are applicable for CAD/CAM system. Distal extension base removable partial dentures exhibit composite type of support, which leads to movement of the denture base under load application and transmission of high amount of stresses to the supporting structures.
\end{abstract}

Aim: The current study was conducted to analyze the stress transmitted to the abutment teeth and the residual ridge by three types of RPDs of different materials; Conventionally manufactured metallic Co-Cr RPDs, and two thermoplastic RPD materials; Acetal (Polyoxymethylene; POM) and a modified PEEK (Poly-Ether-Ether-Ketone) material (BioHPP; Biocompatible high performance polymer) distal extension RPD frameworks both manufactured by computer aided design and computer aided manufacturing (CAD/CAM) system as two esthetic prosthetic materials.

Methods: Strain gauge technology was used to assess micro-strains induced to the denture supporting structures for the three fabricated RPDs groups. Master casts of ten patients with mandibular bilateral distal extension (the remaining teeth extending from left $1^{\text {st }}$ premolar to right $1^{\text {st }}$ premolar) were used so that each cast was duplicated into 4 casts; three of these casts were used for manufacturing of acetal and BioHPP frameworks by CAD/CAM system, and conventional CoCr RPD frameworks. The fourth cast was duplicated to obtain acrylic cast with movable acrylic abutment teeth over which the three RPDs (two metal-free and one metallic RPDs) of each case were seated and tested. The microstrain of the supporting structures was recorded on bilateral and unilateral loading.

Results: On bilateral loading: Mean value of microstrains recorded at the abutments was -63.75 and -18.75 at the ridge for Co-Cr group; For acetal group, it was -91.25 at the abutments and 18.94 at the ridge; For BioHPP group, microstrain was -106 at abutments, while it was 37.15 at the ridges. On unilateral loading: For Co-Cr group, microstrains recorded at right abutment was -52 , while it was -6 at left abutment, and at right ridge it was -16.5 and -2 at left ridge; For acetal group, microstrains recorded at right abutment was -176 and -10 at left abutment, and at right ridge it was 17 and 4.5 at left ridge; For BioHPP group, microstrains recorded at right abutment was -284 , while it was 10.5 at left abutment, and at right ridge it was 50.5 and 6.5 at left ridge.

* Assistant Professor of Dental Biomaterials, Faculty of Dentistry, Mansoura University, Egypt. 
Conclusion: Co-Cr RPDs group showed the least stresses transmitted to the supporting tissues followed by Acetal RPDs, while BioHPP RPDs group showed the highest mean values of microstrain induced to the abutment teeth and the residual ridge.

KEY WORDS: Distal extension RPDs-Metal-free dentures-Acetal-BioHPP- Co-Cr-CAD/ CAM-Stress analysis

\section{INTRODUCTION}

There are several factors affecting the magnitude of the stresses transmitted to the supporting structures among of which are the materials from which the RPDs were manufactured. Direct retainers having stress releasing action that decrease the tipping stresses transmitted to the abutment teeth during tissue ward movement of the partial denture by moving into deeper undercut (Grasso et al., 1991).

The most important purposes of removable partial dentures (RPDs) are the preservation of the supporting structures, improve masticatory function and aesthetics (Zlataric et al., 2002, DubravkaKnezovic et al., 2003, Igarash et al. 1999). There are different forces tending to cause movement of the denture base under masticatory loading resulting in damage of the supporting structures and patient uneasiness, hence these forces should be accurately controlled. Distal extension bases exhibit merged type of support gained from both the teeth and residual ridges (Craig and Farah 1978). The last tooth adjacent to distal extension base (abutment) is subjected to load in both anteroposterior and lateral orders, in addition to the rotational movement. Direct retainers transmit these forces to the abutment teeth and may cause early crash of its supporting tissues (Lammie and Laird 1986).

The forces transmitted to oral tissues or those induced by occlusion or prosthetic appliances were assessed using several stress analysis techniques. Among these techniques photoelasticity, finite element analysis, mechanical dials gauges and electric resistance strain gauge (Delong and Douglas 1983). Strain gauge analysis has been used widely in stress investigation studies with dissimilar prosthodontic appliance designs. This technique is one of the common methods used for dental stress analysis that can conquer many of the shortcomings of other methods (Cehreli and Iplikcioglu 2002). If a wire insulated by a packing material is cemented to the structure for measuring strain, and the resistance change of the wire during loading was measured, this change in resistance can be transformed into strain measurements (Dally et al., 1962). The widely used types of electrical resistance strain gauge are the bonded wire and the metal foil strain gauges. The bonded wire strain gauges consist of a fine wire laid in zigzag mannerand sandwiched between two strips of paper. In the metal foil strain gauges, a very thin foil used instead of the fine wire which has greater heat dissipation properties (Lundgreen and Laurell 1998). The strain gauges can only sense deformations of the surface to which they are bonded (Jedyankiewicz, 1992). Electrical resistance strain gauges were used in the form of pressure transducers to study some designs for distal extension partial dentures and to analyze the pressure distribution on the supporting structures. Also, were used when using tissue conditioners and the effect of occlusal scheme on pressure distribution of complete denture supporting tissues (Inou et al ., 1996, Shohet 1969).

Esthetics is a matter of great concern for patients receiving dental treatment, especially prosthetic treatment. Co-Cr alloys have been commonly used as RPD frameworks since many decades, but these appliances have some problems such esthetically undesirable exhibit of metal clasps and producing hypersensitivity to patient allergic to Co-Cr (Wapner 1991, Misch 2005). Hence, it has 
seems necessary to rehabilitate partially edentulous patients with removable partial dentures (RPDs) constructed from materials that meet the aesthetic needs required to ensure patient satisfaction with dental treatment and designed on biomechanical principles to preserve the remaining tissues. Newly, growing request on aesthetic pleasurable dental curative has led to prevalent use of non-metal clasp dentures (NMCDs) (Iwata 2016, Fueki et al., 2014) and introduction of numbers of materials used as NMCDs, which are mainly polyamide (nylon) resin and polyester or polycarbonate injection-molded thermoplastic denture base resins (Wada et al.2015). Historically, the first NMCDs in the 1950s were made of polyamide resin, which was developed to deal with the allergic reaction to residual monomers after the polymerization of acrylic resin (Stafford and Huggett 1986). This advantage has also been utilized subsequently for avoiding metal allergy (Kuwahara et al., 2004). The use of RPDs made either from resin alone or a combination of resin and metal is now rapidly gaining popularity among general dentists and is considered to be superior to conventional metal-clasp retained RPDs with metal clasps in terms of both esthetics and comfort ( $\boldsymbol{T}$. Suzuki et al., 2011). A problem identified by prosthodontists is that there is no set definition or name for RPDs using thermoplastic resin, which are commonly known as flexible dentures, nonclasp dentures, clasp-free dentures, and metalfree dentures. Recently, "non-clasp dentures" has become the generally used term, but according to the definition in the US GPT-8 Glossary of Prosthodontic Terms, the resin part that extends from the denture base to include the abutment teeth and which is responsible for retention is a structural element that should be called a clasp, and the term "non-clasp" is therefore inappropriate (Glossary of prosthodontic terms. 8th edition, 2005). It was concluded that the thermoplastic material that has a low elastic modulus is easily to manipulate. Also, it is more workable for larger retentive undercuts to improve retention than is the case with acrylic resin and metallic (Co-Cr) clasp design (Alwan and Ismail 2014). Thermoplastic resins could be used in dentistry to make preformed clasps, metal free removable dentures, occlusal splints, synthetic teeth for removable dentures, and implant abutments etc. Most probably, additional chemical development of elastomeric and polymeric materials will increase the domain of clinical applications of thermoplastics in dental field (Negrutiu et al., 2001, Kutsch et al., 2003).

Polyoxymethylene (POM) also known as acetal resin, an injection-molded resin has been introduced as an alternative to conventional PMMA. $\mathrm{POM}$ is formed by the polymerization of formaldehyde. The homopolymer, polyoxymethylene is a chain of alternating methyl groups linked by an oxygen molecule (Fitton et al., 1994) (Fig.1). Acetal resin was considered as substitutive removable partial denture framework material for patients with allergic reactions to $\mathrm{Co}-\mathrm{Cr}$ alloys because of its biocompatibility. It is reported to have a suitably high resilience and modulus of elasticity to permit its employ in the manufacture of retentive clasps, connectors, and support elements for removable partial dentures (Thakral et al., 2012).

A substitutive material; poly-ether-ether-ketone (PEEK) has become widely settled in the medical engineering and it has increasingly been recommended for dental applications. Polyetheretherketone (PEEK) is polymer from the group polyaryletherketone (PAEK) which is a relatively new family of high-temperature thermoplastic polymers, consisting of an aromatic backbone molecular chain, interconnected by ketone and ether functional groups (Fig. 1). Its structure confers outstanding chemical resistance and resistance to thermal and post-irradiation degradation. Its melting temperature is at around $343^{\circ} \mathrm{C}$. PEEK presents a lower solubility and water absorption as compared to current esthetic computer-aided-design/computer-aided-man- 


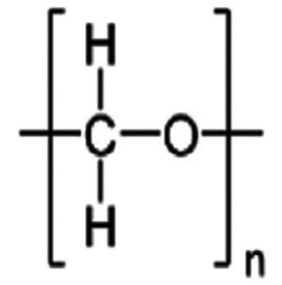

Poly - Oxy - Methylene (POM)

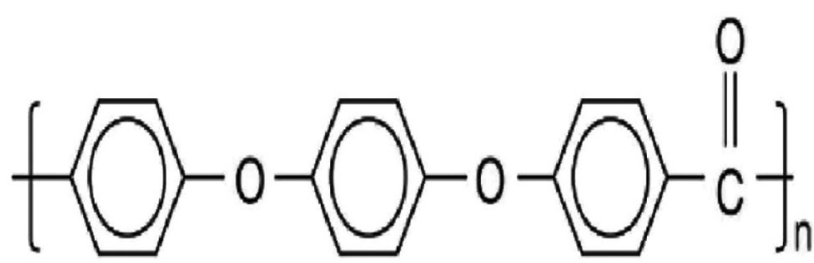

Poly - Ether - Ether - Keton (PEEK)

Fig. (1) Chemical structure of POM and PEEK

ufacturing (CAD / C AM) polymers and is chemically inert (Kurtz and Devine 2007). Also, PEEK is compatible with many reinforcing agents such as ceramic and carbon fibers (Kurtz and Devine 2007).

A modified PEEK (BioHPP) prosthetic material containing $20 \%$ ceramic fillers is a high performance polymer (BioHPP; BredentGmbH, Senden, Germany), which offers good mechanical properties, chemical stability, high biocompatibility, and high temperature resistance. Moreover, the white color of BioHPP framework supplies a diverse esthetic process than the usual metal framework display does (Siewert and Parra 2013, Muhsin et al., 2016).

Nowadays, the CAD-CAM technology became one of the most important developments happened in the dental field at the twenty-one century. Consequently, all dental labs started to shift their services to the digital manufacturing where less material consumed, elimination of inter-operator variation, saving time and effort, and inherent repeatability (Beuer et al., 2008, Kapos et al., 2008,). In addition, frameworks are appropriately finished with minimal porosity and the produced prosthesis have higher precision and strength, as well as excellent esthetics (Jevremović et al., 2011, Williams et al., 2008). C CAD/CAM technology relies on having an accurate three dimension (3D) data acquisition of partially edentulous cast. Dense, accurate and intact point cloud data are essential to create a precise digital model by CAD and the final production by CAM (Wulin 2006). Developments achieved so far include electronic surveying of a three-dimensionally scanned dental cast and the production of successful castings from plastic patterns. Although the castings fabricated by $\mathrm{CAD} /$ CAM-produced patterns are judged to have been acceptable for clinical presentation, but to date, little has been trial-fitted to a patient (Williams et al., 2004, Eggbeer et al., 2004). Acetal and BioHPP prosthetic materials for RPD frameworks are either constructed with the conventional lost wax technique using a vacuum press device or with using computer-aided design and computeraided manufacturing (CAD/CAM) systems (Kurtz and Devine 2007). A major advantage of BioHPP frameworks manufactured by CAD/CAM is that the mechanical properties of BioHPP material are not adversely affected by the milling process as some materials can be. Modified PEEK (BioHPP) can be milled very easily (Whitty 2014).

The aim of the current study was to analyze the stress transmitted to the denture supporting structures (abutment teeth and the residual ridge) in mandibular bilateral distal extension removable partial dentures constructed from Co-Cr by lost wax technique, acetal and BioHPP aesthetic prosthetic materials by CAD /CAM system. 


\section{MATERIALS AND METHODS}

\section{Patient selection}

Ten patients were selected from the removable prosthodontic department, Faculty of Dentistry, Mansoura University. Patients have no systemic diseases relating to bone resorption and the remaining teeth were periodontally healthy without mobility and extending from the first premolar to first premolar of the other side. The functional depth of the floor of the mouth was not less than $8 \mathrm{~mm}$. All patients signed an informed consent form about the purpose, risks and benefits of the research.

\section{Procedures of R P Ds construction}

For all patients, periodontal treatments in terms of oral scaling were done. Maxillary and mandibular preliminary impressions were made to produce diagnostic models. The mandibular diagnostic models were surveyed to draw the survey line and measure the depth of retentive undercut used for the design of R P D. The distal extension removable partial dentures were designed with a hypothetical strategy of stress-releasing design which achieves retention, support, reciprocation, bracing and connection. It was composed of major connector (lingual bar) extended from right to left mandibular first premolar at least $3 \mathrm{~mm}$ away from the gingival margins. The clasp used was RPA; thus a mesial occlusal rest was prepared within the abutment and proximal guiding plane of $1.5 \mathrm{~mm}$ was prepared on the abutment distal surface to be connected with the proximal plate which carries the modified Aker retentive clasp arm to engage mesial retentive undercuts of first premolars. Additional rests were added on the lower canines to act as indirect retainers. Maxillary and mandibular secondary impression was made by medium body elastomeric impression; maxillary impression was poured with hard stone to produce the master model, while the mandibular impression was poured to form master model which is duplicated three times to produce three casts one for construction of each type of RPD frameworks.

\section{Conventional RPD frameworks fabrication}

Mandibular master cast undesirable undercut was block out by wax. The distal half of the facial surface of the first premolar was blocked out for R P A clasp design. The modified master cast was duplicated, then the wax pattern was fabricated, invested, burned out, and casted with chromium cobalt alloy. The metallic RPD framework was tried in the patient mouth, jaw relation was registered, and the upper and lower casts were mounted on a semi-adjustable articulator using maxillary face bow for upper cast and centric interocclusal record for lower one. Artificial teeth were arranged and the mandibular Kennedy Class I RPDs were tried in and processed with heat cured acrylic resin. Intra oral adjustment of occlusion was done using articulating paper and selective grinding when indicated and then the dentures were inserted.

\section{CAD/CAM of Acetal and BioHPP RPD Frame- works}

The Mandibular master cast was fastened on table of the scanner and scanned by desktop structured-light 3D scanner (Shera-Eco Scan 7, SHERA Werkstoff-Technologie $\mathrm{GmbH}$ \& Co. $\mathrm{KG}$, Germany) to produce the 3D model. This was followed by selection of the lateral view to see the model side to select the path of insertion and the 3D model tilted in the sagittal plane. All the undercut areas were selected, red highlighted, and the entire areas selected were flattened to be free of undercuts except the small areas of retentive undercut on the buccal surface of the abutment teeth used for clasp. Creation of relief was done by lifting the meshretainer part $0.5 \mathrm{~mm}$ towards occlusal direction. RPD components were the same as in the conventional frameworks and created by using a pen-tablet as an input device to facilitate designing process. Then, the surface components were converted into a solid 
volume. The sharp angles were then smoothed at peripheries while keeping the framework configuration using smoothing tools. 3D printing of the framework was done by 5-axis milling machine with new optimized CAM software (SHERA EcoMill 5x, SHERA Werkstoff-Technologie GmbH \& Co. $\mathrm{KG}$, Germany) to mill the Acetal and BioHPP materials directly to the desired framework design (Fig.2). The RPD frameworks were tried in the patient mouth (Fig. 3), jaw relation was registered, and the upper and lower casts were mounted on a semi adjustable articulator using maxillary face bow for upper cast and centric interocclusal record for lower one. Artificial teeth were arranged. Mandibular Kennedy Class I RPDs were tried in and processed with heat-cured acrylic resin. Intra oral adjustment of occlusion was done using articulating paper and selective grinding when indicated and then the dentures were inserted.

\section{Acrylic cast fabrication}

An impression was made for the master cast using rubber base impression material. Acrylic $1^{\text {st }}$ premolars (right and left) were chosen similar to the premolars of the patient and their roots were wrapped by $0.3 \mathrm{~mm}$ thickness tin foil and inserted in their corresponding positions in the impression. Molten wax was poured into the impression and processed to obtain acrylic resin cast. The teeth with tin foil spacer were removed from the acrylic cast. The tin foil wrapped around the roots of the teeth was removed. The sockets and roots of the $1^{\text {st }}$ premolars teeth were cleaned from remnants of the tin foil and their sockets were painted with rubber base adhesive. Light body rubber base impression material was injected in the sockets of the teeth and the teeth were immediately repositioned in their sockets inside the light body rubber base material and pressed till its setting. This obtained an experimental cast representing Kennedy class I with the roots of the $1^{\text {st }}$ premolars abutment teeth surrounded by an even layer of rubber base $(0.3 \mathrm{~mm})$ simulating the periodontal ligament.
A plaster index was made for the edentulous ridges, the lingual surface of the anterior part of the ridge behind the anterior teeth and the tongue space of the experimental cast. This index was used to make $2 \mathrm{~mm}$ thickness layer of rubber base to simulate the oral mucosa under the denture bases and major connector. An approximate $2 \mathrm{~mm}$ thickness was removed from the surface of acrylic resin cast of the saddle areas and the position planned for the major connector. Depressions of $2 \mathrm{~mm}$ depth were initially drilled and then joined together. The reduced surface was smoothed and painted with rubber adhesive that allowed drying for 10 minutes. Silicone rubber impression material was pressed against the cast using the plaster index to obtain the rubber layer simulating the oral mucosa. Figure 4, shows the final acrylic cast, $\mathrm{Co}-\mathrm{Cr}$, Acetal, and BioHPP manufactured RPDs.

\section{Installation of the strain gauges}

The strain gauges used in this study were supplied with fully encapsulated grid and attached wires. The gauge length was $2 \mathrm{~mm}$, the gauge resistance was $120.4 \pm 0.4 \mathrm{Ohm}$ and the gauge factor was $2.09 \%$. Four strain gauges were used; two of them were installed in the distal wall of the socket of the two $1^{\text {st }}$ premolars, while the other two gauges were installed on the residual ridge below the central fossa of the left and right $1^{\text {st }}$ molars. The gauges were oriented vertically and attached to their planned positions by a bonding agent. The wires of the strain gauges were impeded in groves created in the cast and fixed in position using self cured acrylic resin. The strain gauges were installed and fixed in position before making the rubber layer that simulates the oral mucosa. A 4 channel strain meter was used to assess the strains induced to distally of the last abutment teeth (premolars) and the residual ridges.

\section{Loading application and microstrain recording}

The acrylic experimental cast with the installed four gauges and the RPD was placed on the lower flat metal plate of a universal testing machine 
(Fig.5). The T-shaped load applicator bar of the testing machine was allowed to seat and touch the denture teeth bilaterally at the point between 2 nd premolar and $1^{\text {st }}$ molar. A load was applied using the universal -testing machine at the point between the 2 nd premolar and the $1^{\text {st }}$ molar bilaterally and unilaterally. The applied load started from zero up to $80 \mathrm{~N}$. The micro strains of the four strain gauges were recorded to measure the strains developed at the distal wall of the socket of the two $1^{\text {st }}$ premolars and at the residual ridge below the central fossa of the 1st molars for each load application. Once the load was completely applied, the microstrain readings were transferred to microstrain units from the four channel strain-meter. Enough time was given to the strain gauges to be in zero balance before making the next reading. The same steps were carried out with each type of the fabricated RPDs. The mean of 5 readings for each channel was calculated to compare between the strains obtained from the three RPDs.

The data were analyzed using ANOVA to test possible difference between groups. Multiple Comparisons were made by Tukey's t-test with statistical significance set at the 0.05 probability level ( $\mathrm{P}$ is significant if $<0.05$ at confidence interval $95 \%)$.

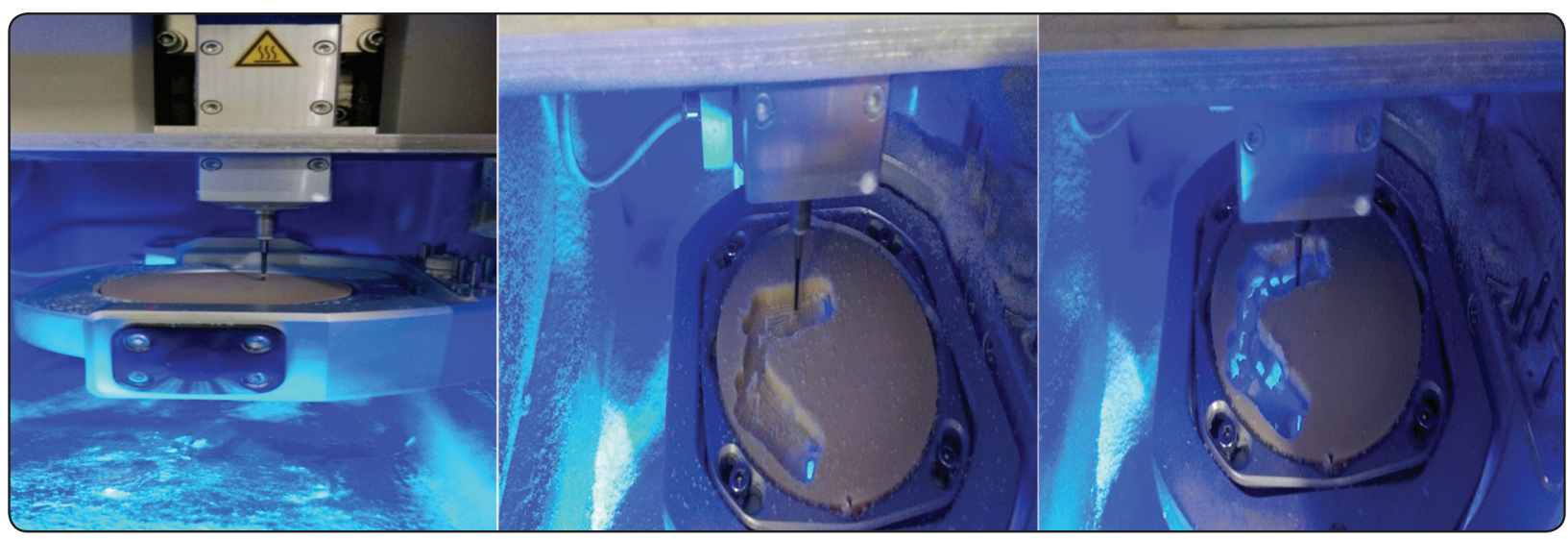

Fig. (2) CAD/CAM manufacturing of Acetal RPD framework

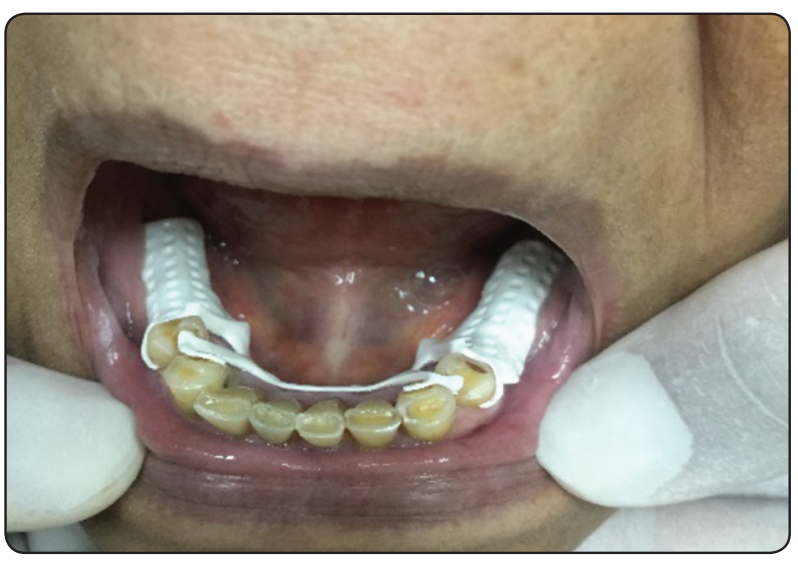

Fig. (3) Framework seated in the patient mouth

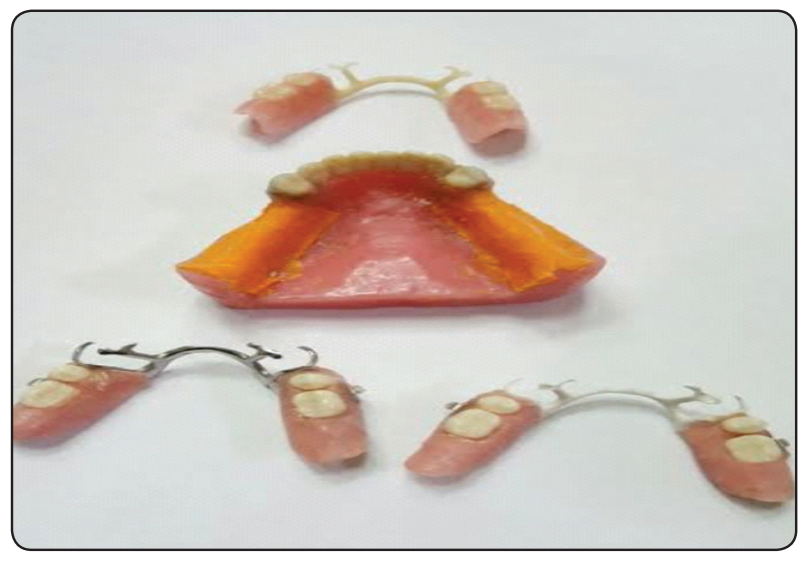

Fig. (4) The duplicated acrylic cast and the three fabricated RPDs 


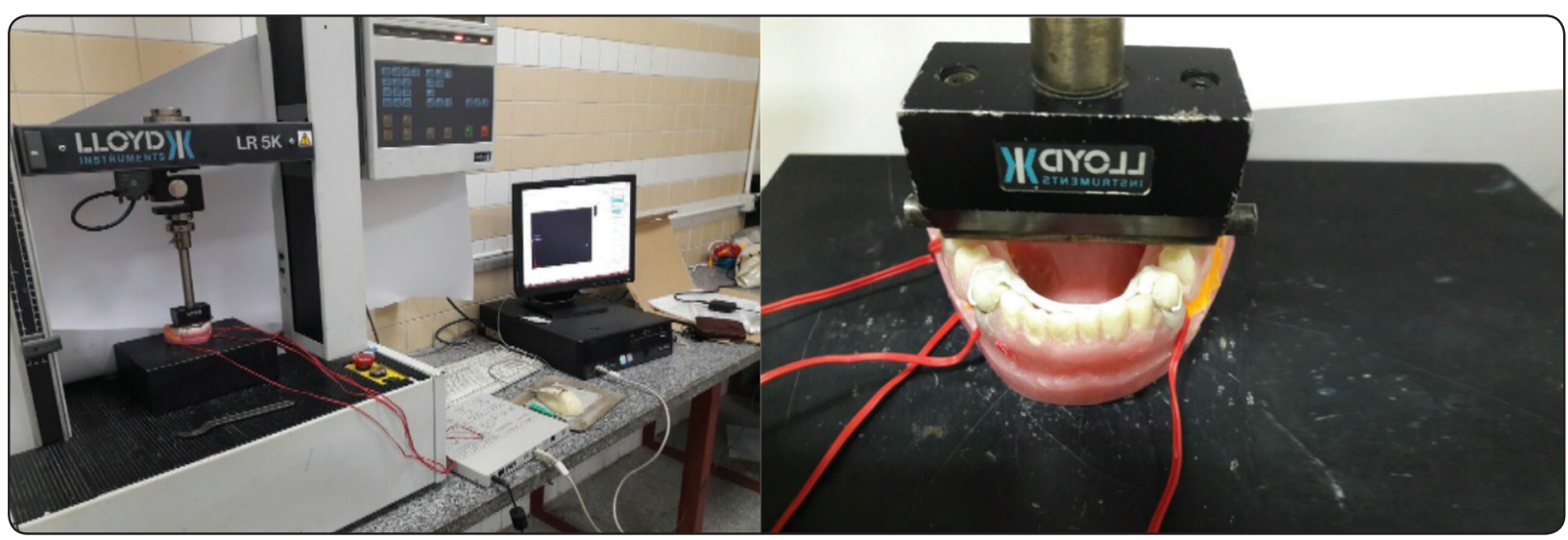

Fig. (5) The universal-testing machine with the model and the installed four strain gauges

\section{RESULTS}

\section{1- Microstrains measured with bilateral load application}

Microstrains measured at the distal aspects of the socket of $1^{\text {st }}$ premolar abutments and the residual ridges under the central fossa of $1^{\text {st }}$ molars for all RPDs groups on bilateral loading were shown in table (1).

TABLE (1) The mean values of micro strains on bilateral load application for the three RPDs

\begin{tabular}{|c|c|c|c|c|}
\hline \multirow{2}{*}{$\begin{array}{c}\text { Measured site } \\
\text { RPD Groups }\end{array}$} & \multicolumn{2}{|c|}{ Abutment } & \multicolumn{2}{c|}{ Ridge } \\
\cline { 2 - 5 } & Mean & SD & Mean & SD \\
\hline Co-Cr & $-63.75^{\mathrm{c}}$ & 1.32 & $-18.75^{\mathrm{b}}$ & 1.32 \\
\hline Acetal & $-91.25^{\mathrm{b}}$ & 1.32 & $+18.94^{\mathrm{b}}$ & 0.81 \\
\hline BioHPP & $-106.00^{\mathrm{a}}$ & 1.80 & $+37.15^{\mathrm{a}}$ & 0.78 \\
\hline LSD & \multicolumn{2}{|c|}{1.371} & 0.919 \\
\hline P value & \multicolumn{2}{|c|}{0.0001} & \multicolumn{2}{c|}{0.0001} \\
\hline
\end{tabular}

-; compressive strain. +; tensile strain.

$a-b=$ Means with the same letter in each column are not significantly different at $\mathbf{P} \leq 0.05$.

LSD $=$ Least Significant Difference .
As shown in table (1):

- On bilateral loading, mean value of microstrains recorded just distal to $1^{\text {st }}$ premolar abutments was -63.75 for Co-Cr RPD group, while it was -91.25 for acetal RPD, and -106 for BioHPP RPD group.

- On bilateral loading, mean value of microstrains recorded at the ridges under the central fossa of $1^{\text {st }}$ molar was -18.75 for Cr-Co group, while it was 18.94 for acetal group and 37.15 for BioHPP RPD group.

- The highest stress transmitted to the supporting structures on bilateral loading was produced by BioHPP RPD group, followed by acetal group, while the lowest values were recorded with $\mathrm{Co}$ Cr RPD group.

- There was a significant difference between all groups regarding the microstrains of the abutment teeth. In regard to the ridge, there was a significant difference between the BioHPP group and both $\mathrm{Co}-\mathrm{Cr} \&$ acetal groups but no significant difference between $\mathrm{Co}-\mathrm{Cr}$ and acetal groups.

\section{2- Microstrains measured with unilateral load application}

Microstrains measured at the distal aspects of 
TABLE (2) The mean values of micro strains on unilateral loading for the three RPDs groups

\begin{tabular}{|c|c|c|c|c|c|c|c|c|}
\hline \multirow{2}{*}{$\begin{array}{c}\text { Measured site } \\
\text { RPD Groups }\end{array}$} & \multicolumn{2}{|c|}{ Right Abutment } & \multicolumn{2}{c|}{ Right Ridge } & \multicolumn{2}{c|}{ Left Abutment } & \multicolumn{2}{c|}{ Left Ridge } \\
\cline { 2 - 10 } & Mean & SD & Mean & SD & Mean & SD & Mean & SD \\
\hline Co-Cr & $-52.00^{\mathrm{c}}$ & 2.58 & $-16.50^{\mathrm{b}}$ & 2.42 & $-6.00 \mathrm{~b}$ & 2.00 & $-2.91 \mathrm{c}$ & 1.92 \\
\hline Acetal & $-176.00^{\mathrm{b}}$ & 3.16 & $17.00^{\mathrm{b}}$ & 2.58 & $-10.00 \mathrm{a}$ & 0.00 & $4.50 \mathrm{~b}$ & 1.50 \\
\hline BioHPP & $-284.00^{\mathrm{a}}$ & 5.16 & $50.50^{\mathrm{a}}$ & 3.69 & $10.70 \mathrm{a}$ & 2.24 & $6.50 \mathrm{a}$ & 1.36 \\
\hline LSD & \multicolumn{2}{|c|}{3.487} & 2.707 & & & & 1.509 \\
\hline P value & \multicolumn{2}{|c|}{0.0001} & 0.0001 & 0.0001 & & 0.0001 \\
\hline
\end{tabular}

-; compressive strain

+ ; tensile strain.

$a-b=$ Means with the same letter in each column are not significantly different at $P \leq 0.05$. LSD $=$ Least Significant Difference .

the socket of left and right $1^{\text {st }}$ premolar abutments, and the right and left residual ridge under the central fossa of $1^{\text {st }}$ molars for all RPDs groups on unilateral loading of right side for all groups were shown in table (2).

As shown in table (2):

On unilateral loading:

* For Co-Cr RPDs group, the mean values of micro strains recorded distal to the right abutment was -52 , while it was -6 at the left $1^{\text {st }}$ premolar. At the ridge under central fossa of right $1^{\text {st }}$ molar was -16.5 , and was -2 at ridge under left $1^{\text {st }}$ molar.

* For acetal group, the mean values of micro strains recorded distal to the right $1^{\text {st }}$ premolar abutment was -176 , while it was -10 for distal to the left $1^{\text {st }}$ premolar. At the right ridge it was 17 , and 4.5 at the left ridge.

* For BioHPP group, the mean values of micro strains recorded distal to the right $1^{\text {st }}$ premolar abutment was -284 , while it was 10.5 for distal to the left $1^{\text {st }}$ premolar. At the right ridge it was 50.5, and 6.5 at the left ridge.

It can be noticed that, the stresses transmitted to the supporting structures of the side where load was applied are much higher than that transmitted to the supporting structures of the other side for all tested groups.

The highest microstrain values of the supporting structures on unilateral loading was produced by BioHPP group, followed by acetal group, while the lowest values were recorded with Co-Cr group.

There was a significant difference between all groups regarding the microstrains of the abutment teeth. In regard to the ridge, there was a significant difference between the BioHPP group and both Co$\mathrm{Cr} \&$ acetal groups but no significant difference between $\mathrm{Co}-\mathrm{Cr}$ and acetal groups.

\section{DISCUSSION}

Combined tooth-tissue support has constantly been a problem that causes higher susceptibility of abutment loss in free-end saddle cases because these dentures are subjected to deleterious forces constantly exerted laterally, obliquely and apically producing torque action on the abutment teeth and traumatization of edentulous mucosa due to the difference in viscoelasticity between the edentulous ridges and the periodontal ligaments (Arda and Arikan 2005). A major concern with the use of a 
distal extension removable partial denture is the abutment wall evaluation especially the distal wall to study the effect of partial dentures on abutment teeth (John et al., 2001). Lower distal extension partial denture was selected for this study because being one of the most frequently used prosthetic restorations; representing a typical treatment problem (Lammie and Laird 1986). For the development and improvement of RPD design, continuous biological and laboratory investigations are necessary. Clinical experience alone is not sufficient documentation to determine the relative merits of any particular RPD philosophy.

In the current study, the three RPDs for the same patient were tested on the same duplicated acrylic cast as this seemed beneficial in providing valid comparative data because the model with the same abutment teeth, ridges, and the same denture components except the material from which the RPDs were manufactured which is the point of the study. Different patients were evaluated to observe the effect of variation in the nature of the teeth, their periodontal support, form and length of their roots, and the form of the residual ridge.

The strain gauge system was used in this study as it was reported to be a stable and accurate system with few problems. The strain gauges assess strains induced into a loaded structure by converting the change in resistance of an electric wire into strain measurement (Cehreli and Iplikcioglu 2002, McKinley 1970). The wire used for the strain gauges was insulated by a packing material as a protection from humidity which was reported to be essential for obtaining reliable recordings (Srinath et al 1984). The sites of the strain gauges used were the same in the acrylic cast for the three RPDs, in an attempt to eradicate the occurrence of imprecise strain recordings. All the strain gauges used in the study exhibited the same dimensions, resistance and gauge factor in order to obtain the same level of sensitivity to the applied load. The gauges were also correctly located, cemented in position and connected in an attempt to eliminate incorrect recordings resulting due to high sensitivity of strain gauges to any variation occurring during load application (Inou et al 1996).

Since the structures supporting distal extension removable partial dentures reveal visco-elastic properties, the model used for this study was fabricated to simulate as much as possible the oral conditions. The roots of the abutment teeth were lined with a $0.3 \mathrm{~mm}$ thickness of silicon rubber material to replicate the thickness and resiliency of the periodontal ligament. The resiliency of the mucosa covering the residual ridge was reported to be greater than that of the periodontal ligament, so the residual ridges were covered by a $2 \mathrm{~mm}$ thickness of silicon rubber material. Bilateral and unilateral loading of the dentures were also performed to simulate the clinical situation as much of the chewing activities are carried out unilaterally.

Inspection of the recorded microstrain results of this study showed that the stresses induced distal to the last abutments and to the residual ridges as a result of bilateral and unilateral loading were significantly higher with BioHPP RPDs group compared to acetal and $\mathrm{Co}-\mathrm{Cr}$ groups. This could be attributed to the high stiffness of the Co-Cr alloy. One of the main desirable characteristics of major connectors is that it should be rigid. Rigidity of the major connector fabricated from $\mathrm{Co}-\mathrm{Cr}$ alloy allows stresses that are applied to any component of the partial denture to be effectively distributed over the entire supporting area, including abutment teeth, underlying bone and soft tissues. Rigid major connectors resist deflection, deformation, and torquing forces that could be transmitted to the abutment teeth and other structures as destructive forces. The major connector is thus the most vital component critically subjected to maximal stress concentration and deflection due to various forces acting on it (Stewart et al., 2000). Literature 
claims that a rigid lingual bar is more desirable for withstanding horizontal stress and restraining excess movements of abutments (Henderson 1973). The rigid connectors proved to be the most effective in transmitting applied occlusal forces to the contralateral side of the framework (Green and Hondrum 2003). Behr et al., in a retrospective study evaluating the clinical performance of $\mathrm{Co}-\mathrm{Cr}$ RDPs, estimated a 10-year survival rate of $90 \%$; however, traditional RDPs do not always comply with the patient's esthetic demands for a metal-free restoration.

Acetal RPDs showed stress transmission to the supporting tissues which was in between the best one (Co-Cr) and the worst one (BioHPP). Also, there was no significant difference between acetal and $\mathrm{Co}-\mathrm{Cr}$ regarding microstrain of the ridge. This may be attributed to presence of some rigidity within the acetal RPD which is greater than BioHPP RPD and less than that of the CO-Cr RPD. This rigidity was so obvious by manual inspection and testing of all RPD types; this is because acetal has a high degree of crystallinity and is known as one of the strongest and stiffest thermoplastic materials (Erich 1998). Thakral et al., 2012, mentioned that acetal resin has a sufficiently high resilience and modulus of elasticity to allow its use in the manufacture of the elements for removable partial dentures. Also it is strong, resists fracturing, and does not wear during occlusal forces and consequently will maintain vertical dimension over long periods of time. Acetal has been used in dentistry all over the world as a substitute for acrylic resins and metals in many prosthetic applications. The most widely used appliances were the esthetic clasps of partial removable dental prostheses (Arda and Arikan 2005, Chu and Chow 2003, Sykes et al., 2002, Turner et al., 1999). Saad swedan et al., 2014, evaluated radiographically the effect of distal extension removable partial denture either constructed from thermoplastics acetal or vitallium materials on bone height change of abutment teeth.
They concluded that thermoplastic mandibular distal extension removable partial denture material was superior to vitallium material regarding the preservation of abutment alveolar bone. They differ with the present study in the method of manufacturing of acetal RPDs, the design, and the point of evaluation. A modified PEEK (BioHPP) in conjunction with regular acrylic artificial teeth and commonplace heat-cured denture base acrylic resin was used as an alternative RDP framework material. Due to its white color and high strength, it exhibits a perfect balance of the properties desirable to frameworks, lightweight for improved patient comfort, no thermal or electrical conductivity, non-allergenic, and metal-free denture framework with no metal taste. In addition, BioHPP is shock absorbent during chewing, have high resistance to abrasion and decay (Zoidis et al 2016). The result of the current study showed that BioHPP group recorded the highest microstrain values for the supporting tissues; this may be attributed to the low modulus of elasticity and the high flexibility which produce high stress on the supporting tissues with load application. The greatest damage a partial denture can produce is that which results from a flexible major connector. Flexibility concentrates forces on individual teeth or the edentulous ridge, causing damage to the abutment teeth, impingement and injury to the soft tissues, thus gradually leading to the resorption of the residual ridge (Stewart et al., 2000).

Zoidis et al., 2016, evaluated a clinical report presents a modified poly-ether-ether-ketone (PEEK) as an alternative material for the fabrication of distal extension removable dental prosthesis (RDP) frameworks. After a short-term, 1-year clinical follow-up, there was no framework breakage with good clasp retention. They thought that BioHPP frameworks had the beneficial for the periodontal health of the abutment teeth as its elasticity might reduce the stress on the abutment teeth and the distal torque. Therefore, it could be hypothesized 
that BioHPP would be a viable alternative RPD material for abutments with reduced periodontal support when restoring distal extension cases. They also concluded that, due to the lack of solid clinical evidence, BioHPP should not be considered as a substitute framework material for a well-designed Cr-Co RDP and it should probably be considered as an alternative RDP framework material for patients with taste sensitivity or allergies to conventional Cr-Co frameworks or used as a clasp material with rigid frameworks. BioHPP is a material recently introduced in dentistry. Unfortunately, there is lack of studies evaluating the behavior of this material.

The results of this study is in agreement with Kenji et al., 2014, they published an article titled "Clinical application of removable partial dentures using thermoplastics". Non-metal clasp dentures were classified into two types: one with a flexible structure that lacks a metal framework and the other having a rigid structure that includes a metal framework. According to current prosthetic principles, flexible non-metal clasp dentures are not recommended as definitive dentures, except for limited cases such as patients with a metal allergy. Rigid non-metal clasp dentures are recommended in cases where patients will not accept metal clasps for esthetic reasons. Non-metal clasp dentures should follow the same design principles as conventional RPDs using metal clasps. NMCDs that do not include a metal structure and are not rigid are indicated as interim dentures or spare dentures for patients with metal allergy, patients with few missing anterior teeth, and patients with few missing teeth with occlusal support, patients for whom esthetics must be given top priority, and patients who do not consent to the preparation of abutment teeth.

RPDs using thermoplastic resin have some limitations as revealed by prosthodontists (Ohkubo et al., 2012). The first issue is that some RPDs using thermoplastic resin do not conform to the principles regarding the standard RPD design, and that the use of such RPDs may seriously affect the periodontal tissues of abutment teeth and the residual ridge. As this procedure is simple and is not covered by national health insurance, if patients' demands and desires for a good esthetic appearance are given precedence and such RPDs are used outside the scope of their intended use, this would be a serious disadvantage for patients. It has also been pointed out that depending on the material, problems including fracture of the resin clasp, roughening of the polished surface of the denture base, or discoloration of denture base resin may occur, and treatment such as reline or repair may be difficult. In practice, various problems do occur after denture fitting in at least some patients, and while the evidence from clinical trials is limited, there is a possibility that the inappropriate use of RPDs using thermoplastic resin may become a social issue. If this situation is left unaddressed, it may decrease public trust in dental treatment. In light of these circumstances, the Japan Prosthodontic Society (JPS) has cautioned against the regular clinical use of RPDs using thermoplastic resin, stating that "Although so-called non-clasp dentures have the positive advantage of being effective in restoring external appearance, they have the disadvantage that if they are used in the wrong patients they may cause major damage, including abnormal resorption of the residual ridge and increase of movement of the abutment teeth, and their indications should be scientifically verified in the future". In a clinical guideline formulated in 2008, JPS stated that "Application of flexible dentures solely from the viewpoint of anterior esthetics is not recommended."

\section{CONCLUSION}

Under the present conditions, it can be concluded that:

- RPDs fabricated of CAD/CAM BioHPP modified PEEK material are higher strain inducer to the supporting tissues than those 
fabricated of conventional $\mathrm{Co}-\mathrm{Cr}$ or $\mathrm{CAD} /$ CAM acetal RPDs.

- The highest microstrain mean value was recrorded with BioHPP RPDs group which would be more hazard to the supporting tissues than other types.

- Acetal group showed stress transmission to the supporting tissues which was between the best one (Co-Cr) and the worst one (BioHPP). Also, there was no significant difference between acetal and $\mathrm{Co}-\mathrm{Cr}$ groups regarding microstrain of the ridge.

\section{RECOMMENDATIONS}

- In cases in which the patient is comfortable with a metal clasp, non-allergic to $\mathrm{Co}-\mathrm{Cr}$, and suitable for a well-designed Co-Cr RPD; then dentist should not go toward acetal or BioHPP RPDs fabrication.

- Acetal resin should probably be considered as an alternative RDP framework material in patients with taste sensitivity or allergies to conventional Co-Cr frameworks.

- BioHPP should probably be considered as clasp material for NMCDs that include a metal framework to provide rigidity (rigid non metal clasp dentures) in cases in which the patient is uncomfortable with a metal clasp running through area that would affect esthetic appearance

- Non-rigid NMCDs cannot be recommended as definitive dentures in light of current prosthetic principles, with the exception of patients with metal allergies and some others.

- Methods of reline and maintenance should be understood with reference to the properties of the different materials used.

- Further longterm clinical evidence is needed to consolidate the scientific data.

\section{REFERENCES}

- $\quad$ Alwan S, Ismail I. Retentive forces, tensile strength and deflection fatigue of Acetal thermoplastic clasp material in comparison with cobalt-chromium alloy. J BaghColl Dentistry 2014;26:59-66.

- Arda T, Arikan A. An in vitro comparison of retentive force and deformation of acetal resin and cobalt-chromium clasps. J Prosthet Dent 2005;94:2670-74.

- Behr M, Zeman F, Passauer T, et al. Clinical performance of cast clasp-retained removable partial dentures: a retrospective study. Int J Prosthodont 2012;25:138-44.

- Beuer F, Schweiger J, Edelhoff D. Digital dentistry: an overview of recent developments for CAD/CAM generated restorations. Brit dent J 2008;204(9):505-11.

- $\quad$ Cehreli M C, Iplikcioglu H. In vitro strain gauge analysis of axial and off-axial loading on implant supported fixed partial dentures. Implant Dent 2002;11:286.

- Chu C H, Chow T W. Esthetic designs of removable partial dentures. Gen Dent 2003;51:322-4.

- $\quad$ Craig R G, Farah J W. Stress from loading distal extension removable partial denture. J Prosthet Dent 1978;39:274.

- Dally JW and Riley WF. Experimental stress analysis. $2^{\text {nd }}$ ed. McGraw Hill publishing co., London, 1962.

- Delong R, Douglas W H. Development of an artificial oral environment for the testing of dental restoratives: biaxial force and movement control. J Dent Res 1983 Jan; 62(1):32-6.

- Dubravka Knezovic Zlataric, Asja Celebic, Slaven Brujic. Alveolar Bone Loss on Abutment and Non-Abutment Teeth in Relation to Removable Partial Denture Wearing. A Six Month Follow Up Study. Acta Stomatol Croat 2003;37 (2):185-88.

- $\quad$ Eggbeer D, Williams R, Bibb R. A digital method of design and manufacture of sacrificial patterns for removable partial denture metal frameworks. Quintessence J Dent Technol $2004 ; 2$ : 490-9.

- Erich Wintermantel S. Biokompatible Werkstoffe and Bauweisen. $2^{\text {nd }}$ ed. 1998: Springer.

- Fitton JS, Davies EH, Howlett JA, Pearson GJ. The physical properties of a polyacetal denture resin. Clin Mater 1994;17:125-9. 
- Fueki K, Ohkubo C, Yatabe M, Arakawa I, Arita M, Ino $\mathrm{S}$, et al. Clinical application of removable partial dentures using thermoplastic resin-Part I: definition and indication of nonmetal clasp dentures. J Prosthodont Res 2014; 58:3-10.

- Glossary of prosthodontic terms. 8th edition. J Prosthet Dent 2005;94:1-85.

- Grasso JE and Miller EL. Removable partial prostodontics. Mosby 1991;35-67.

- Green LK, Hondrum SO. The effect of design modifications on the torsional and compressive rigidity of U-shaped palatal major connectors. J Prosthet Dent 2003; 89(4):400-7.

- Henderson D. Major connectors for mandibular removable partial dentures: design and function. J Prosthet Dent 1973;30(4):532-48.

- Igarash Y, Ogata A, Kuroiwa A, Wang C H. Stress distribution and abutment tooth mobility of distal extension removable partial dentures with different retainers: An in vivo study. J Oral Rehab 1999;26:111.

- Inou S, Rawano F, Nagao K, Matyusmoto N. An in vitro study of the influence of occlusal scheme on the pressure distribution of complete denture supporting tissue. Int $\mathbf{J}$ Prosthod $1996 ;$ 9:179.

- Iwata Y.Assessment of clasp design and flexural properties of acrylic denture base materials for use in nonmetal clasp dentures. J Prosthodont Res 2016;60:114-22.

- Jedyankiewicz N M. A practical guide to technology in dentistry. $1^{\text {st }}$ ed.1992.

- Jevremović D, Kojić V, Bogdanović G, Puškar T, Eggbeer D, Thomas D, Williams R. A selective laser melted Co-Cr alloy used for the rapid manufacture of removable partial denture frameworks-initial screening of biocompatibility. J Serb Chem Soc 2011;76 (1): 43-52.

- John J, Gangadhar SA, Shah I. Flexural strength of heatpolymerized polymethyl methacrylate denture resin reinforced with glass, aramid or nylon fibers. J Prosthet Dent 2001;86(4):424-7.

- Kapos T, Ashy L M, Gallucci G O, Weber H P, Wismeijer D. Computer-aided design and computer-assisted manufacturing in prosthetic implant dentistry. The International journal of oral \& maxillofacial implants 2008;24:110-7.
- Kenji Fueki, Chikahiro Ohkubo, Masaru Yatabe, Ichiro Arakawa, Masahiro Arita, Satoshi Ino, Mutsuo Yamauchi. Clinical application of removable partial dentures using thermoplastic resin-Part I: Definition and indication of non-metal clasp dentures. J Prosthodont Res 2014 ; 58 (1):3-10.

- $\quad$ Kurtz S M, Devine J N. PEEK biomaterials in trauma, orthopedic, and spinal implants. Biomaterials 2007; 28:4845-69.

- $\quad$ Kutsch K, Whitehouse W, Schermerhorn K. The evolution and advancement of dental thermoplastics. Dental Town 2003;4(2):52-6.

- Kuwahara F, Nagahama K, Kitahara M, Wada S, Makimura $\mathrm{K}$, Kimura et al. A case of using non-metal clasp partial denture for the patient with metal allergy. Nichidai Koko Kagaku 2004 ; 30:134-9.

- Lammie G A, Laird W R E. Osborne and Lammie's partial dentures. $4^{\text {th }}$ ed. Blackwell scientific publications, Oxford, London 1986;295.

- $\quad$ Lundgreen D, Laurell L. Occlusal force pattern during arch extension. J Oral Maxillofac Surg 1998;27:435.

- McKinley J W. Fundamentals of stress analysis. Matrex Publisher Inc. Oreason 1970;235.

- Misch C E. Dental Implant Prosthetics, $1^{\text {st }}$ ed. St. Louis: Elsevier Mosby. 2005.

- Muhsin S, Hatton P, Johnson A, Sereno N, Wood D. Retentive Force of Novel Polyetheretherketone Clasp Design. Poster presented at $3^{\text {rd }}$ Meeting of the IADR Asia Pacific Region; 35th Annual Meeting of the IADR Korean Division. 2016, June.

- $\quad$-Negrutiu M, Bratu D, Rominu M. Polymers used in technology of removable dentures. Romanian Journal of Stomatology 2001;4:30-41.

- -Ohkubo C, Yatabe M, Arita M. Present status and clinical problems of non-metal clasp dentures - can it become one choice for prosthetic rehabilitation? Ann Jpn Prosthodont Soc 2012;4:63-4.

- Shohet H. Relative magnitudes of stress on abutment teeth with different retainers. J Prosthet Dent 1969;21:267.

- $\quad$ Siewert B, Parra M. A new group of material in dentistry. Peek as a framework material used in 12-piece implantsupported bridges. Z Zahnarzt Implantol 2013;29:148-59. 
- Srinath L S, Raghavon M R, Lingalah K, Gargesha G, Ramachandra K. Experimental stress analysis. $2^{\text {nd }}$ ed. McGraw-Hill Publishing Co., London, 1984; 245.

- $\quad$ Stafford G D, Huggett R. The use of nylon as a denturebase material. J Dent 1986;14:18-22.

- Stewart KL, Rudd KD, Kuebker WA. Clinical removable partial prosthodontics. $2^{\text {nd }}$ ed. St. Louis: C.V. Mosby; 2000.

- Sykes LM, Dullabh HD, SukhaA K. Use of technopolymer clasps in prostheses for patients due to have radiation therapy. Sadj 2002;57:29-32.

- T. Suzuki H, Shimpo N, Kitano M, Sato Y, Kawai Y, Kanki et al. A questionnaire survey on the thermoplastic dentures. Ann Jpn Prosthodont Soc 2011;3:133.

- Thakral G, Aeran H, Yadav B, Thakral R. Flexible Partial Dentures-A hope for the Challenged Mouth. People's Journal of Scientific Research 2012;5(2):55-9.

- $\quad$ Turner J W, Radford D R, Sherriff M. Flexural properties and surface finishing of acetal resin denture clasps. J Prosthodont 1999;8:188-95.

- Wada J, Fueki K, Yatabe M, Takahashi H, Wakabayashi N. A comparison of the fitting accuracy of thermoplastic denture base resins used in non-metal clasp dentures to a conventional heat cured acrylic resin. Acta Odontol Scand 2015;73: 33-7.
- Wapner K L. Implications of metallic corrosion in total knee orthoplasty. Clin Orthop Relat Res 1991;271:12-20.

- Whitty T. PEEK- A new material for CAD/CAM dentistry. eLABORATE 2014; March / April: 32-6.

- Williams R, Bibb R, Rafik T. A technique for fabricating patterns for removable partial denture frameworks using digitized casts and electronic surveying. J Prosthetic Dent 2004;91:85-8.

- Williams RJ, Eggbeer D, Bibb R. CAD/CAM Rapid Manufacturing Techniques in the Fabrication of Removable Partial Denture Frameworks. Quintessence J Dental Technol 2008;6 (1):42-50.

- Wulin. Preliminary Study on CAD/CAM of Removable Partial Denture Framework. China Medical University, PhD thesis, 2006.

- Zlataric DK, Celebic A, Valentic M. The effect of removable partial dentures on periodontal health of abutment and non-abutment teeth. J periodontol 2002;73(2): 137-44.

- Zoidis P,Papathanasiou I,Polyzois G. The Use of a Modified Poly-Ether-Ether-Ketone (PEEK) as an Alternative Framework Material for Removable Dental Prostheses: A Clinical Report. J Prosthodont 2016;25(7):580-4. 